\title{
Highlights of the New OECD Report on Transfer Pricing
}

\author{
Helmut Becker, Deloitte \& Touche, Düsseldorf
}

Just recently the OECD adopted the basic principles of the new OECD Report on transfer pricing. The highlights of that report are very interesting.

For multinationals, it is most important which transfer pricing method will be applied, and who decides on its application. The OECD Report now 'encourages' - more can a gremium to achieve a compromise not say - the tax administration 'to take into account the taxpayer's commercial judgment about the application of the arm's length principle in their examination practices and to undertake their analyses of transfer pricing from that perspective'. That clearly states the preference of the taxpayer's choice.

Another important question is to whom the burden of proof belongs. The tax authorities of the different countries seem to be of different opinions. 'Some member countries are of the view that Article 9 of the OECD model tax convention establishes burden of proof rules in transfer pricing cases which override any contrary domestic provisions'. This opinion relies on the better arguments: Starting point is Article 7 of the model convention allocating the primary right to tax a profit to that state and that enterprise where the profit has been earned. This principle has exceptions; one is defined by a permanent establishment in the other country, another is based on Article 9 for adjustments of non-arm's length transactions. If, however, someone relies on an exemption, he has to prove that the prerequisites of that exemption are met. Therefore, that state which internationally wants to make an adjustment, has to prove that this is justified. Some states still deny that. However, even those states have accepted that principle in competent authority procedures. 'In competent authority proceedings, the state that has proposed the primary adjustment bears the burden of demonstrating to the other state that the adjustment is justified both in principle and as regards the amount'.

The OECD once again has confirmed that 'transfer pricing is not an exact science, but does require the exercise of judgment on the part of both the tax administration and taxpayer'. Therefore, 'the consideration of transfer pricing should not be confused with the consideration of problems of tax fraud or tax avoidance'.

Another highlight in the expressed acceptance of business strategies. Those 'business strategies would take into account many aspects of an enterprise, such as innovation and new product development, degree of diversification, risk aversion, assessment of political changes, input of existing and planned labor laws and other factors bearing upon the daily conduct of business'. These strategies also may apply to low price strategies, which some Japanese groups follow to win shares in the world market.

A serious controversy was going on whether profit methods can be accepted. The majority of the multinationals commenting on the discussion draft of the OECD Report denied that (see Intertax 1995. S256). Now, a compromise has been achieved. 'The only profit methods that satisfy the arm's length principle are those consistent with the profit split method or the transactional net margin methods (both combined under the title transactional profit methods) as described in these guidelines. In particular, so called 'comparable profits methods' or 'modified cost plus/resale price methods' are acceptable only to the extent that they are consistent with these guidelines'. Therefore, the new transactional net margin methods have become of high interest.

Most important, is that 'a transactional profit method examines the profits that arise from particular controlled transactions'. Therefore, no longer profits - based on profit level indicators - are compared, but transactions with their profits. Article 9 of the model convention 'requires that the profits arising from particular controlled transactions be compared to the profits arising from comparable transactions between independent enterprises'. However, those transactional profit methods should be applied only in exceptional situations. 'In such cases of last resort, practical considerations may suggest application of a 
transactional profit method either in conjunction with transactional transaction methods or on its own. However, even in the case of last resort, it would be inappropriate to automatically apply a transactional profit method without first considering the reliability of that method'.

As these methods need a certain degree of sophistication, 'consequently, transactional profits methods should never be used by tax administrations, if they do not yet have the necessary institutional framework to ensure that the proper precautions are taken. This would include the existence of an effective administrative appeals mechanism'. Apart from that the tax administrations applying such method 'should be particularly conscious of its burden in demonstrating ... that such approach is being appropriately applied and achieves the best approximation of an arm's length pricing in all facts and circumstances of the case. Tax administrations also should be conscious of the relevant burden of proof rules in applicable arbitration proceedings'.

Another important item addresses the penalties which are of high concern for the multinationals and for the states not charging penalties. Penalties may serve many administrative or procedural aspects of a tax system. 'Nonetheless, member countries agree on the following conclusions':

- 'First, imposition of a sizable 'no-fault' penalty based on the mere existance of an understatement of a certain amount, would be unduly harsh when it is attributable to good faith error rather than negligence or an intent to avoid tax.'

- 'Second, it would be unfair to impose sizable penalties on taxpayers that made a reasonable effort in good faith, to set the terms of their transactions with related parties in a manner consistent with the arm's length principle'.

- 'In particular, it would be inappropriate to impose a transfer pricing penalty on a taxpayer for failing to consider data to which it did not have access, or for the failure to apply a transfer pricing method that would have required data that was not available to the taxpayer'.

Penalties not in accordance with these principles are defined as 'overly harsh' and 'excessive' and are contradicting to Article 9 of the model convention.

All these statements and conclusions were not yet part of the former discussion draft. Therefore, these highlights represent a considerable improvement. 